\title{
MODELING THE DEVELOPMENTS IN URBANISATION AND RELATIONSHIP WITH VEGETATION COVER IN ALANYA
}

\author{
Buket IŞLER ${ }^{1}$, Zafer ASLAN $^{2}$ \\ ${ }^{1}$ Department of Computer Engineering, Graduate School, Istanbul Aydın University, 34295, Istanbul, Turkey \\ buketkilic1@stu.aydin.edu.tr \\ ${ }^{2}$ Department of Computer Engineering, Faculty of Engineering, Istanbul Aydın University, 34295, Istanbul, Turkey \\ zaferaslan@aydin.edu.tr
}

KEY WORDS: Remote Sensing, Urbanization, EVI, Wavelet-ANN Modelling.

\begin{abstract}
:
The increase in the world population and the migration of people from rural to urban areas causes an increase in artificial surfaces and causes many negative effects on the ecosystem, regional climate variations and global diversity. Nowadays, as the effects of climate change are felt more and more, it has gained importance in researches on this subject. Therefore, the estimation of the change in the vegetation density for the coming years and the determination of the land use / land cover (LULC) change in cities are very essential for urban planning. In this study, the effects of regional urbanization on vegetation are examined by using satellite data and atmospheric variables. In the vegetation analysis, multi-time index values obtained from TERRA-MODIS satellite, EVI (Enhanced Vegetation Index) and LST (Land Surface Temperature) were taken into account between the years of 2005 and 2018 in Alanya, Turkey. Temperature and precipitation were selected as the atmospheric variables and expected variations in EVI value until 2030 were estimated. In the study employed a wavelet-transformed artificial neural network (WANN) model to generate long-term (12-year) EVI forecasts using LST, temperature and precipitation. The relationship between land use / land cover and urbanization is investigated with NDBI (Normalized Difference Built-up Index) data obtained from the Landsat 8 OLI / TIRS satellite sensor. The simulation results show that The EVI value, which was 0.30 in 2018, will decrease to 0.25 in 2030.
\end{abstract}

\section{INTRODUCTION}

Owing to advancing technological tools and software, comprehensive data analysis and predictions for the future have reached promising levels. Ensuring the continuity of human life is perhaps one of the most important current problems of humanity. Hence, is a topic that has been researched by scientific circles for years. The deterioration of natural resources, the destruction of vegetation, urbanization, increasing population density, changing climates because of human activities signal an emergency for the future of humanity. Studies based on satellite data and artificial intelligence technologies reveal the urgency of the situation. Despite the warnings of the scientific community to take immediate action, global warming remains to be of low priority for millions of global citizens around the world. On the other hand, the $1.5^{\circ} \mathrm{C}$ of Global Warming based on the Special Report devised by the Intergovernmental Panel on Climate Change (IPCC) in 2018 based on the examination of over 6.000 scientific studies, was approved by governments in South Korea (IPCC, 2018). According to the report, human beings have caused the air temperature to warm up to $1{ }^{\circ} \mathrm{C}$ higher compared to the pre-industrial period. The greenhouse gases generated because of industrial and agricultural activities as well as the high levels of energy consumption caused by human activities have increased the concentration of $\mathrm{CO} 2, \mathrm{~N} 2 \mathrm{O}$ and $\mathrm{CH} 4$ in the atmosphere (IPCC, 2018). Climate change resulting from global warming manifests itself with events such as drought, desertification, imbalance, and deviations in precipitation as well as floods, typhoon, storm, tornado and so on. Vegetation is a critical component of the global ecosystem. It plays a key role in the protection of soil and water as well as in the prevention of desertification in arid and semi-arid regions (Mohammad and Adam, 2010; Zhu and Zhu, 2012; Huang et al., 2017). Due to the importance of the subject in terms of the health of the living, especially of human beings, research on the effects of urbanization on LULC planning and climate change is increasing and gaining importance. There is lots of remote sensing data for investigating vegetation changes (Kayman and Sunar,2015; Narayan et al., 2016,). LST is an index used in the study of urban development and is an important source of data that helps us to recognize the physical, environmental, and climatic characteristics of the earth's surface (Weng et al., 2004, 2018). Preserve of green areas is the key point against LST risk (Bozorgi,2018). Another index used in vegetation monitoring is EVI. EVI is an 'optimized' index designed to observe land use / land cover changes and is also a good indicator for observing EVI, forest damage and changes [Mondal, 2011; Nguyen et al.,2020]. Within the scope of the study, all parameters used in the research were arranged and analysed with the codes prepared in MS Excel, SPSS, Visual Studio and MATLAB R2012 programming languages. NARX artificial neural network model is used for EVI estimation. NARX is a good method for analysing nonlinear data. (Menezes, 2008; Shatnawi and Qdais,2019). In addition, a hybrid model has been developed using Wavelet transform and artificial neural networks to improve prediction performance If two data groups are to be analysed together, it is known that the developed hybrid models give more successful results than the individually applied models (Alves and Lopes, 2017; Anshuka et al., 2019). In the paper, Alanya district were examined using satellite data and atmospheric variables. EVI and LST multiple time index values obtained from the MODIS/ TERRA satellite between 2005 and 2018 were used in the vegetation analysis. Temperature and precipitation were chosen as atmospheric variables, and expected variations of the EVI value up to 2030 were estimated. It is aimed that the study will 
contribute to sustainable development by estimating vegetation density until 2030.

\section{DATA}

\subsection{Study Area}

Alanya, one of the districts of Antalya, is located in the Mediterranean Region. Located in the east of Antalya, Alanya is $135 \mathrm{~km}$ from the city centre. It is surrounded by the provinces of Manavgat in the west of the district, Gündoğmuş in the north, Gazipaşa in the east and the Mediterranean in the south (Dinç, 2020). Its area is $1582 \mathrm{~km} 2$. Geographical Location Coordinates for Antalya Alanya; Latitude: 36.5507 Longitude: 31.9803. The location map is given in Figure 1. According to TURSTAT data, Alanya population, which was 312 thousand 319 in 2018, rose to 327 thousand 503 with an increase of $4.86 \%$ (TURKSTAT,2018).

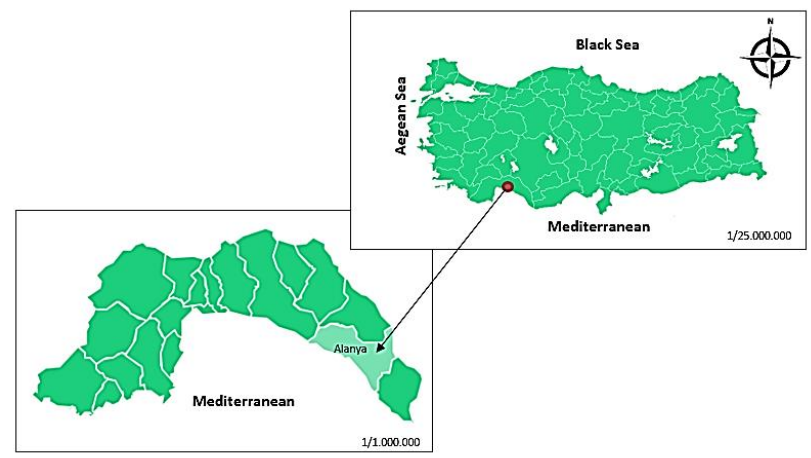

Figure 1. Location map of Alanya

The Mediterranean climate is dominant in Alanya. According to 2005-2018 Turkish State Meteorological Service (TSMS) data, the average annual temperature is around $19.5{ }^{\circ} \mathrm{C}$. In August, which is the hottest month of the year, the average annual temperature is $30^{\circ} \mathrm{C}$. In January, the annual average temperature is $12.6{ }^{\circ} \mathrm{C}$ and it is the coldest month of the year. The temperature of Alanya does not fall below $11^{\circ} \mathrm{C}$ in the winter months, ensuring a warm winter season. The total monthly average rainfall values in Alanya are $893.7 \mathrm{~kg} / \mathrm{m} 2$ (Figure 2).

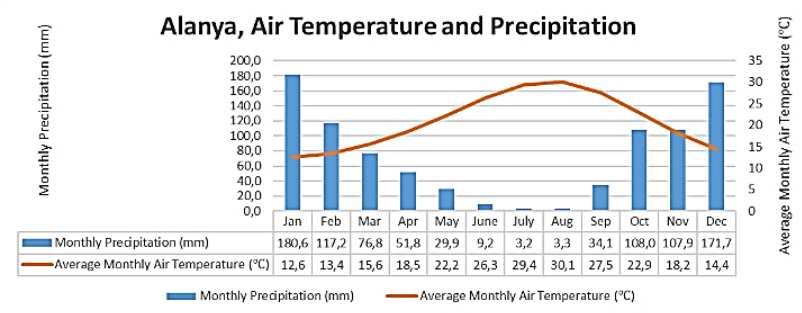

Figure 2. Average monthly air temperature and monthly precipitation from 2005 to 2018

Alanya is a region with the most fertile lands of the Mediterranean region in terms of both its climate and its location. For this reason, the types of plants grown are diverse. The forests in Alanya province constitute $0.5 \%$ of the country's forests. Antalya governorship reported that 750 hectares of land are afforested every year in Alanya. The proportion of the area covered by each class aggregated to level 1 is shown in Figure 3.

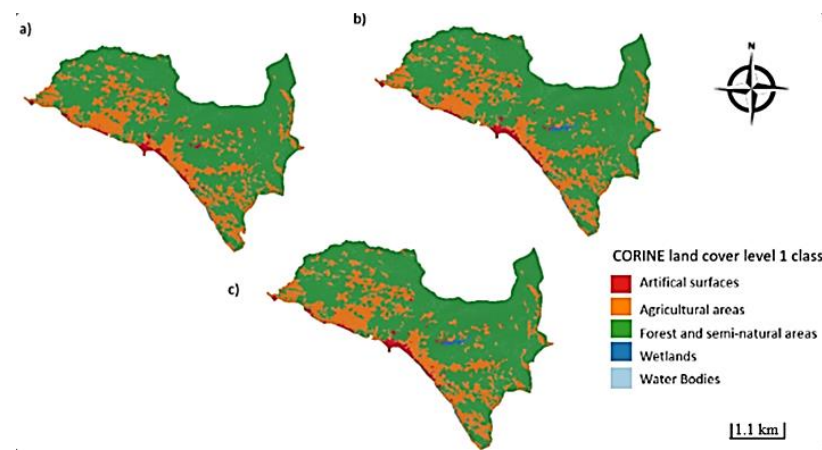

Figure 3. CORINE, LULC maps obtained as a result of classification process; (a): CLC2006, (b): CLC2012, (c): CLC2018)

According to CORINE, forest and semi-natural areas increased by 34 percent from 2006 to $2012.3 \%$ decrease was observed in 2018. Water bodies also increased by 0.33 percent in 2006 until 2018. It is striking that urbanization has increased in the region. Artificial surfaces have increased by 0.35 percent until 2018. In addition, agricultural surfaces decreased by 0.99 percent until 2018 (Table 1).

\begin{tabular}{|l|l|l|l|}
\hline & 2006 & 2012 & 2018 \\
\hline Artificial Surfaces (1) & 1,98 & 2,22 & 2,33 \\
\hline Agricultural Areas (2) & 26,24 & 25,34 & 25,25 \\
\hline Forest and Semi-natural Areas (3) & 71,32 & 71,66 & 71,63 \\
\hline Water Bodies (5) & 0,46 & 0,79 & 0,79 \\
\hline
\end{tabular}

Table 1. Temporal percentage change of LULC according to the CORINE land cover index

As given in Figure 4, the highest average EVI value between 2005 and 2018 was found as 0.32 in 2011, 2012 and 2013. There was $2 \%$ decrease in 2014 until 2018, the value was found as 0.30 in 2018 .

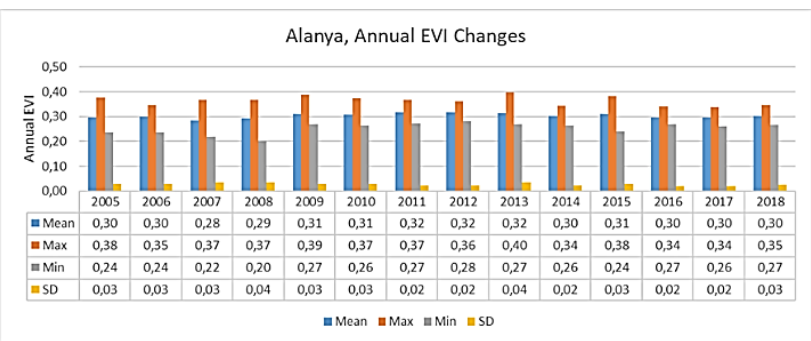

Figure 4. Annual EVI change from 2005-2018

In LST change, it is seen that the temperature decreased in 2011, 2012 and 2013 compared to other years (Figure 5). LST values have increased since 2015 and is reached their highest value in 2018.

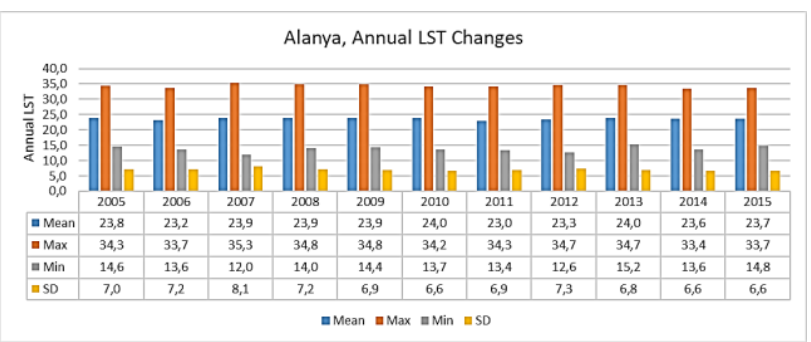

Figure 5. Annual LST change from 2005-2018 


\subsection{Data Type}

EVI: Researches with remote sensing technologies have rapidly increased due to provide to easily analysis on land cover / land use drought risk assessment, natural resource management and agricultural (Dikici and Aksel, 2020). In this study, satellite data on EVI and LST as well as station data have been analysed together with temperature and precipitation. Urbanization and climate change scenarios of Alanya districts will be established for the year 2030. As mentioned before, the study was carried out using the data obtained in the years from 2005 to 2018. In this research, MODIS EVI data with a 250-meter (m) spatial resolution and 16 days of temporal resolution were taken into account (Didan, 2015). EVI is an 'optimized' index designed to improve the sensitivity of high biomass regions, to decompose from background signals of vegetation, to isolate vegetation signals, and to monitor vegetation by reducing atmospheric effects. EVI is a good indicator for observing forest damage and changes (Mondal, 2011). The EVI derived from MODIS Terra MOD13A3 is calculated by equation 1 (Huete et al., 2012; Galvão et al., 2011; Shao et al., 2016; Çelik, 2016).

$$
E V I=G \cdot \frac{(N I R-R E D)}{(N I R+C 1 \cdot R E D-C 2 \cdot B L U E+L)}
$$

$$
\begin{array}{ll}
\text { where } & \mathrm{G}=\text { a gain factor }(2.5) \\
\mathrm{NIR}=\text { near infrared } \\
\mathrm{RED}=\text { reflection rate } \\
\mathrm{C} 1, \mathrm{C} 2=\text { aerosol resistance parameters }(\mathrm{C} 1=6 \text { and } \\
\mathrm{C} 2=7.5) \\
\mathrm{L}=\text { canopy (vegetation) value }
\end{array}
$$

It takes a constant value. EVI values are between -1 and 1 in vegetation pixels, where healthy vegetation generally falls between the values of 0.20 to 0.80 (Sinergise, 2020).

LST: MODIS LST products are composed of data from the daily 1-kilometer LST product and stored on a 1-km Sinusoidal grid as the average values of clear-sky LSTs during an 8-day period (Didan, 2015). LST is an important data source that helps us recognize the physical, environmental and climatic characteristics of the Earth's surface (Wan and Hulley, 2015). In this research, the EVI was used to examine the relationship between LST and land use/land cover. It is obtained by evaluating the surface and atmosphere interactions with energy flows between the atmosphere and the earth together (Mannstein, 1987; Sellers et al., 1988). However, LST measurements are only possible for clear sky conditions. The emissivity-corrected LSTs were calculated as equation 2 (Artis and Carnahan,1982);

$$
L S T=\frac{\mathrm{Tc}}{1+\left(\lambda * \frac{T c}{p}\right) 1 n \varepsilon}
$$

$$
\begin{aligned}
& \text { where } \quad \begin{array}{l}
\lambda=\text { wavelength of emitted radiance }(10.6 \mu \mathrm{m}) \\
\mathrm{p}=\mathrm{h} * \mathrm{c} / \sigma\left(1.438^{*} 10-2 \mathrm{~m} . \mathrm{K}\right) \\
\sigma=(1.38 * 10-23 \mathrm{JK}-1) \\
\mathrm{h}=\text { Planck's constant }(6.626 * 10-34 \mathrm{~J} . \mathrm{s}) \\
\mathrm{c}=\text { Velocity of light }\left(2.998^{*} 108 \mathrm{~ms}-1\right)
\end{array}
\end{aligned}
$$

Surface observations, air temperature and precipitation data of the determined test sites were obtained with the records at the TSMS. Total rainfall and temperature data for the selected districts on a daily, monthly and annual scale covers a period of 14 years $(2005-2018)$.
NDBI: In the study, NDBI values were used to determine the change of urban areas over time (Zha et al., 2003). This index was developed by 2003 in order to automatically determine urban areas using satellite images. It is used to determine residential areas by proportioning the differences of spectral reflections (equation 3).

$$
N D B I=\frac{(M I R-N I R)}{(M I R+N I R)}
$$

where

$$
\begin{aligned}
& \mathrm{MIR}=\text { mid-infrared } \\
& \mathrm{NIR}=\text { near }- \text { infrared }
\end{aligned}
$$

Normalize Difference Build-up Index value lies between -1 to +1 . Negative value of NDBI represent water bodies whereas higher value represents build-up areas. NDBI value for vegetation is low.

Temperature and Precipitation: Precipitation and temperature are the most important factors for the growth and development of plants (TSMS,2018). When the plant density at the equator and the poles is evaluated, the importance of temperature becomes even clearer. Also, the plant density is higher in summer than in winter. In addition, in many ecosystems, especially in grasslands and cultivated areas, seasonal plant growth is related to wet weather (TSMS,2018). Surface observations, air temperature and precipitation data of the determined test sites were obtained with the records at the TSMS. Total rainfall and temperature data for the selected districts on a daily, monthly and annual scale covers a period of 14 years (2005-2018).

\subsection{Missing Data Treatment}

Completion of missing data plays an important role in the success of the method. Missing data on variables with environmental factors negatively affect estimation studies (Haworth and Cheng, 2012). EVI and LST missing data were found by taking the average of the previous and the following data. EVI, LST missing data analysis. EVI, LST missing data analysis for Alanya is given in Table 2. Precipitation and Temperature data were obtained by TSMS and total data size are 5050 and 5088 respectively.

\begin{tabular}{|c|c|c|c|}
\hline & & \multicolumn{2}{|c|}{ Missing Data } \\
\hline Variables & $\mathrm{N}$ & $\mathrm{N}$ & Rate (\%) \\
\hline EVI & 210,000 & 2030 & 1 \\
\hline LST $\left({ }^{\circ} \mathrm{C}\right)$ & 31,556 & 1551 & 4,9 \\
\hline
\end{tabular}

Table 2. EVI and LST missing value analysis

\section{METHOD}

\subsection{Artificial Neural Network}

Artificial neural networks and the research field of artificial intelligence that emerged after the mathematical modelling of the human brain's specific features such as learning and deriving new knowledge from past experiences. ANN is formed based on the connection of artificial nerve cells to each other in various ways and usually has a layered structure (Gulbag and Temurtas, 2006). Artificial neural networks are used in many sectors including prediction, modelling and classification applications. Five basic parameters are taken into consideration while constructing ANN in the science of engineering, which is formed by an effort to model the structure of our biological nervous system. ANN consists of inputs, weights, transfer function, activation function and outputs. 
Inputs: This is the first layer in the neural network. It receives input signals and transmits them to the next layer. Those shown by $\mathrm{X}$ in the figure are inputs.

Weights: Weight values corresponding to inputs. A weight indicates the strength of the connection between units. Weights close to zero mean that changing this input will not change the output. Increasing the value of negative-weighted inputs means that production will decrease. In other words, the weight value determines how much influence the input will have on the output. Transfer Function: It is the function that converts input data to output data and calculates net input. Four types of transfer functions are widely used: Unit step (threshold), sigmoid, piecewise linear and Gaussian and addition functions.

Activation Function: The function produces the output data suitable for the input data. Activation functions must be nonlinear and continuously distinguishable. In this study, tangent sigmoid activation function was used.

Outputs: Outputs are the last data obtained as a result of activation process. The data is sent back to the outside world or cell.

In this study, NARX artificial neural networks were used for EVI estimation. NARX is a dynamic artificial neural network model and is generally used in the modelling of inputs and outputs in nonlinear systems (Menezes and Barreto, 2008).

\subsection{Wavelet Transformation}

In determining climate change and the process of urbanization, more than one nested parametric variable should be examined. Due to the chaotic nature of the variables, the likelihood of predicting events depending on a specific time period decrease (Labat et al., 2005). Land use / land cover, leaf plant index, precipitation, population density, number of buildings, etc. as well as local and temporal changes of data are also crucial for determining the future strategies of countries. In this study, a hybrid modelling system was developed with Wavelet transform and ANN to increase the predictive success of the data. The Wavelet transformation, which will be used in this thesis, was first used by Alfred Haar in 1909 as the term "wavelet" in his doctoral thesis. Over time, many important researchers such as Daubechies, Coifman and Wickherhouser have gained significant momentum. With the wavelet analysis, the missing time information is obtained in the Fourier analysis, which was previously developed. In other words, in wavelet analysis, it is a kind of transformation that allows us to look at a time scale perspective of a signal that changes over time (non-stationary). In this way, we can monitor the characteristics of an event such as slope, fracture, sudden change, start and end.

There must be a wavelet function $(\psi(\mathrm{x}))$ used in wavelet analysis (Percival and Walden, 2002). Analysis is performed by shifting the time domain and scaling the wavelet function over time.

Mathematically represented, the wavelet transform is as follows:

$$
\Psi_{(a, b)}(t)=\frac{1}{\sqrt{a}} \psi\left(\frac{\mathrm{t}-\mathrm{b}}{a}\right)
$$

where $\quad \psi_{-}((\mathrm{a}, \mathrm{b}))=$ continuous wavelet transforms $\mathrm{a}=$ scaling parameter $\mathrm{b}=$ conversion parameter $\Psi=$ wavelet function (main wavelet)

\section{ANALYSIS}

Many studies in the prediction based have shown that hybrid model improves prediction performance (Wang et al., 2013; Rout et al., 2014). In the light of these data, a hybrid model which was predicted to increase the success of estimation has been developed. In this study, EVI, LST, temperature and precipitation values were subdivided into wavelets with Discrete Wavelet Transform (DWT). Results are shown in Table 3. Attributes of the data were obtained with the statistical procedures applied on the obtained data and the new data were given as input parameters to the ANN model. Choosing the appropriate main wavelet according to the characteristics of the data and level plays an important role in terms of analysis performance (Emhan, 2013). EVI, LST, temperature and precipitation data were used in the study with 'd4' wavelet from Daubechies main wavelet family.

\begin{tabular}{|c|r|r|r|r|}
\hline Components & \multicolumn{1}{|c|}{ EVI (t) } & \multicolumn{1}{c|}{ LST } & Temp $\left({ }^{\circ} \mathrm{C}\right)$ & $\begin{array}{r}\text { Precp. } \\
(\mathrm{kg} / \mathrm{m} 2)\end{array}$ \\
\hline$d 1$ &, 02 &, 02 &, 02 &, 01 \\
\hline$d 2$ &, 01 &,- 08 &,- 03 &,- 03 \\
\hline$d 3$ & $\mathbf{- , 2 1}$ &, 01 &,- 18 &, 02 \\
\hline$d 4$ & $\mathbf{- , 3 4}$ &,- 03 &,$- \mathbf{1 5}$ &, 05 \\
\hline$d 5$ &, 01 & $\mathbf{- , 1 3}$ &, 01 &,- 03 \\
\hline$d 6$ &, 01 &, 03 &, 09 & $\mathbf{, 1 2}$ \\
\hline$d 7$ &,- 04 &,- 05 & $\mathbf{- , 1 8}$ & $\mathbf{, 1 3}$ \\
\hline$a 7$ &,- 01 & $\mathbf{- , 1 2}$ &,- 02 & $\mathbf{3 0}$ \\
\hline$s$ &, 48 &, 18 &, 28 &,- 18 \\
\hline
\end{tabular}

Table 3. Correlation coefficients (r) between EVI, LST, Temperature, Precipitation and wavelet details

Note: * The BOLD values indicate the best correlation results for each evaluation metrics.

According to the discrete wavelet analysis findings, large-scale events and their roles show a decreasing trend the whole period. Small and mesoscale factors play an important role on EVI in Alanya during the entire study period. 2005-2014 data (240 data) were used for training, 2015-2018 data (96 data) were used for testing and validation. The data were determined as $60 \%$ of training, $40 \%$ of verification and testing. The best result is obtained that hidden neuron number is 9 . $R$ value is 0.88 (Table 4).

\begin{tabular}{|c|c|c|c|c|c|c|c|c|}
\hline \multirow{3}{*}{$\begin{array}{l}\text { Method } \\
\text { Hidden } \\
\text { neurons }\end{array}$} & \multicolumn{8}{|l|}{ NARX } \\
\hline & \multicolumn{2}{|l|}{3} & \multicolumn{2}{|l|}{6} & \multicolumn{2}{|l|}{9} & \multicolumn{2}{|l|}{12} \\
\hline & MSE & $R$ & MSE & $R$ & MSE & $R$ & MSE & $R$ \\
\hline Training & $2.6 \mathrm{E}-4$ & 0,81 & $2.7 \mathrm{E}-4$ & 0,81 & $1.9 \mathrm{E}-4$ & 0,91 & $2.2 \mathrm{E}-4$ & 0,85 \\
\hline Validation & $3.3 \mathrm{E}-4$ & 0,84 & $2.1 \mathrm{E}-4$ & 0,86 & $2.3 \mathrm{E}-4$ & 0,85 & $2.3 \mathrm{E}-4$ & 0,86 \\
\hline Test & $2.6 \mathrm{E}-4$ & 0,85 & $2.4 \mathrm{E}-4$ & 0,83 & $3.5 \mathrm{E}-4$ & 0,81 & $2.6 \mathrm{E}-4$ & 0,82 \\
\hline Output & $2.8 \mathrm{E}-4$ & & $2.5 \mathrm{E}-4$ & & $2.4 \mathrm{E}-4$ & & $2.6 \mathrm{E}-4$ & \\
\hline
\end{tabular}

Table 4. Comparison of mean square error (MSE) and correlation coefficient (r) values of the number of neurons in the WANN system

After the DWT analysis, the estimated results of the EVI values of Alanya for the period between 2019-2030 were given in Figure 6. As a result of WANN analysis, the average EVI value for 2030 was found to be 0.25 .

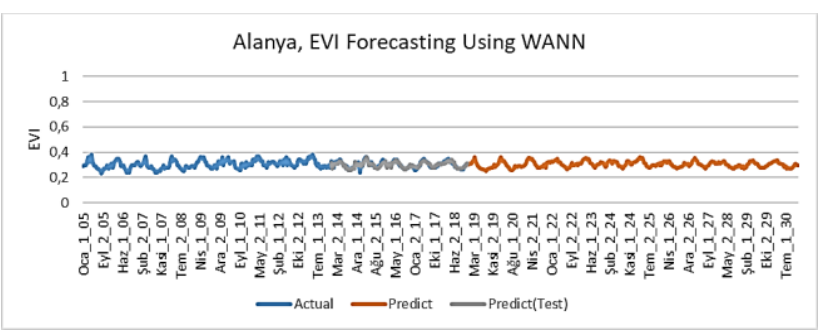

Figure 6. Forecast using WANN between 2019-2030 
Determining the relationship between NDBI, LST and EVI is a good indicator for understanding the level of urbanization(Malik,2019). Relationship between NDVI and NBDI has also been observed during the period of 2014-2018. Relationship between NDBI and EVI was developed and is showing strong negative correlation $\mathrm{R} 2=0.987$ for whole period (Figure 7.). The negative correlations between EVI and the daily mean air temperature $(\mathrm{r}=-0,57)$ are slightly more stronger than those between EVI and LST (r=-0,55). EVI have shown strong positive relationship with precipitation during the whole period. The strong positive correlation found between LST and NDBI means more be the built-up area high is the surface temperature $(\mathrm{r}=0,70)$. (not shown).

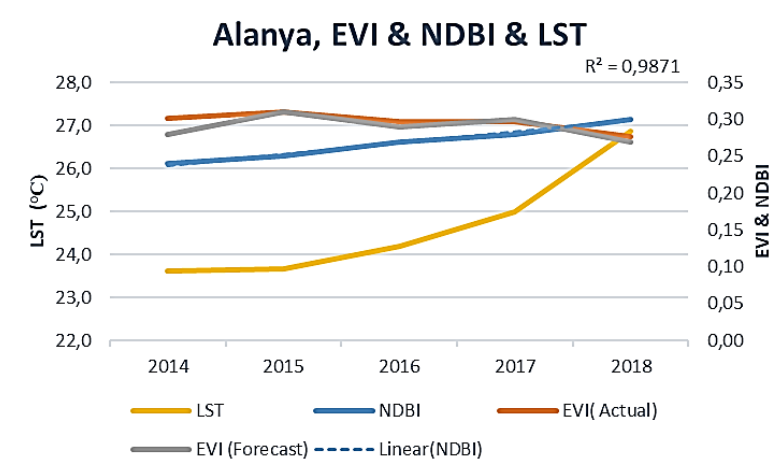

Figure 7. Line plot of the mean annual value for the years 2014-2018 $($ alpha $=0,01)$

\section{CONCLUSIONS AND DISCUSSIONS}

This study provides some pre-results of future effects of climate change and the role it plays in problems resulting from urbanization by using some current analysis methods. Alanya is the most populated district of Antalya and it has been selected as the main study region. Determining the current situation in this district, revealing the change of vegetation density depending on time, predicting the future situation are important in terms of LULC. A hybrid method has been developed to detect the change in vegetation density within the scope of this study. ADD and NARX models are handled in an integrated manner and the error rate between the real data and the data desired to be predicted has been tried to be minimized. According to the results of the research, it was determined that the predictive ability of the hybrid model increased as the correlation value between the original EVI and LST, temperature and precipitation data with discrete wavelet analysis increased (İşler and Aslan, 2021). WANN model results shown that decrease in the EVI value in Alanya. The average EVI was 0.30 in 2018. As a result of WANN analysis, the average EVI value for 2030 was found to be 0.25 . EVI value is expected to decrease by $16 \%$ in 2030 compared to 2018. Estimation of future vegetation levels is an important indicator of our predictions concerning urbanization and climate change problems. Streiling and Matzarakis found that the temperature difference between a wooded area and a non-wooded area in Freiburg, Germany is $1^{\circ} \mathrm{C}$ and that the temperature decreases as the number of trees increases (Streiling and Matzarakis, 2003). Many studies show that air temperatures are lower in green areas than in structural areas. The correlation results between EVI, LST, precipitation and temperature parameters used in the research are similar to many studies in the literature (Narayan et al., 2016; Kamali et al., 2021). As a result of analysis, there was found a negative correlation between EVI, LST and air temperature. Due to the decrease in plant density, it is predicted that the air temperature will increase in the study area (Tonyaloğlu,2019). In addition, it can be emphasized that an increase in the incidence of unstable and severe weather events (flood, overflow, etc.) is expected (Aslan et al., 2019). On the other hand, the strong positive correlation found between EVI and Precipitation. It was also found that there was a strong positive correlation between LST - NDBI means more be the built-up area high is the surface temperature.

Arberti stated that there was an inverse relationship between urbanization and vegetation (Arberti, 2008). The effects of human activities and climate factors have a negative impact on grassland productivity as already known from many studies (Yin et al., 2014). It is predicted that the average value ratio of vegetation by 2030 will decrease and accordingly, it has been concluded that the urbanization process of the Alanya study area will continue rapidly.

\section{ACKNOWLEDGEMENTS}

This paper is related with sub chapters of the on-going Ph.D. thesis of M.Sc. B. ISLER. The authors would like to express their thanks to Istanbul Aydın University (IAU) Graduate Institute, BAP (Scientific Research Foundation). Prof. Dr. Ali GÜNEŞ (IAU), Prof. Dr. Filiz SUNAR (ITU) and Turkish State Meteorological Service (TSMS) for their comments and support for the study. Co-author, Z. Aslan would like to thank to ICTP Simons Associateship Program.

\section{REFERENCES}

Alberti, M., 2008: Advances in Urban Ecology (first ed.), Springer-Verlag, US, p. 366.

Alves, E.D.L., Lopes, A., 2017: The Urban Heat Island Effect and the Role Vegetation to Address the Negative Impacts Climate Changes in a Small Brazilian City, Atmosphere, 8(2), 18.

Anshuka, A., van Ogtrop, F.F., Vervoort, R.W., 2019: Drought forecasting through statistical models using standardised precipitation index: a systematic review and meta-regression analysis. Natural Hazards, 1-23.

Artis, D.A., Carnahan, W.H., 1982: Survey of emissivity variability in thermography of urban areas. Remote sensing of Environment, 12(4), 313-329.

Aslan, Z., Erdemir, G., Feoli, E., Giorgi, F., Okcu, D., 2019: Effects of climate change on soil erosion risk assessed by clustering and artificial neural network. Pure and Applied Geophysics, 176(2), 937-949.

Bozorgi M., Nejadkoorki F., Mousavi M.B., 2018: Land surface temperature estimating in urbanized landscapes using artificial neural networks, Environ Monit Assess, 190, 250, 2018.

Çelik, M.A., 2016: Bitki İndeks Modelleri (NDVI, EVI, VCI) Kullanılarak Akdeniz Bölgesi'nde Kuraklık Analizi (20002014). Phd, T.C. Kahramanmaraş Sütçü İmam University, Sosyal Bilimler Enstitüsü, Kahramanmaraş.

Didan, K., 2015: MOD13Q1 MODIS/Terra Vegetation Indices 16-Day L3 Global 250m SIN Grid V006. NASA EOSDIS Land Processes DAAC.

Dikici, M., Aksel, M., 2020: Evaluation of Two Vegetation Indices (NDVI and VCI) Over Asi Basin in Turkey. Teknik Dergi, 32(4). 
Emhan, Ö., 2017: Yukarı- Aşağı İmleç Hareketine İliş̧kin EEG Kayıtlarının Ayrık Dalgacık, Knn ve Dvm ile Sınıflandırılması. MSc, Dicle University.

Galvão, L.S., Santos, J.R., Roberts, D., Breunig, D.A., Toomey, F. M., Moura, M.Y.M., 2011: On Intra-Annual EVI Variability İn The Dry Season of Tropical Forest: A Case Study with MODIS and Hyperspectral Data, Remote Sensing of Environment, 115, Ss. 2350-2359.

Gulbag, A., Temurtas, F., 2006: A study on quantitative classification of binary gas mixture using neural networks and adaptive neuro-fuzzy inference systems. Sensors and Actuators B 2006;115(1):252-62.

Haworth, J., Cheng, T., 2012: Non-parametric regression for space-time forecasting under missing data. Computers, Environment and Urban Systems, 36(6), 538-550.

Heymann, Y., Ch, Steenmans., G, Croissille., M, Bossard., 1994: CORINE Land Cover. Technical Guide. EUR12585, Office for Official Publications of the European Communities (Luxembourg).

Huang, S., Ming, B., Huang, Q., Leng, G., Hou, B., 2017: A case study on a combination NDVI forecasting model based on the entropy weight method. Water Resources Management, 31(11), 3667-3681.

Huete, A., Didan, K., Miura, T., Rodriguez, E. P., Gao, X., Ferreira, L.G., 2012: Overview of the radiometric and biophysical performance of the MODIS vegetation indices. Remote Sensing of Environment. 83, 195-213.

Intergovernmental Panel on Climate Change (IPCC), 2014: Climate change 2018: Special Report: Global Warming of $1.5^{\circ} \mathrm{C}$. Retrieved from https://www.ipcc.ch/sr15/ (accessed 28.01.2019).

Kamali, Maskooni, E., Hashemi, H., Berndtsson, R., Daneshkar, Arasteh, P., Kazemi, M., 2021: Impact of spatiotemporal landuse and land-cover changes on surface urban heat islands in a semiarid region using Landsat data. International Journal of Digital Earth, 14(2), 250-270.

Labat, D., Ronchail, J., Guyot, J.L., 2005: Recent advances in wavelet analyses: Part 2-Amazon, Parana, Orinoco and Congo discharges time scale variability, Journal of Hydrology, 314, 289311.

Malik, M. S., Shukla, J. P., Mishra, S., 2019: Relationship of LST, NDBI and NDVI using Landsat- 8 data in Kandaihimmat watershed, Hoshangabad, India.

Mannstein, H., 1987: Remote Sensing Applications in Meteorology and Climatology, Volume 201 ISBN: 978-94-0108225-9.

Menezes, J.M.P, Barreto, G.A, 2008: Long-term time series prediction with the NARX network: An empirical evaluation, Neurocomputing, 71(16-18), 3335-3343.

Mohammad, A.G., Adam, M.A., 2010: The impact of vegetative cover type on runoff and soil erosion under different land uses. Catena, 81(2), 97-103.
Mondal, P., 2011: Quantifying surface gradients with a 2-band Enhanced Vegetation Index (EVI2), Ecological Indicators, 11(3), 918-924.

Narayan, K., Khanindra, P., Abhisek, C., Sahoo, S., 2016: Urban heat island explored by corelationship between land surface temperature vs multiple vegetation indices. Spat. Inf. Res. http://dx. doi.org/10.1007/s41324-016-0049-3.

Nguyen, L.H., Joshi D.R., Clay D.E., Henebry G.M., 2020: Characterizing land cover/land use from multiple years of Landsat and MODIS time series: A novel approach using land surface phenology modeling and random forest classifier. Remote Sensing of Environment, 238, 1-14.

Percival, D.B., Walden, A.T., 2012: Wavelet Methods for Time Series Analysis. Cambridge University Press, second edition.

Rout, M., Majhi, B., Majhi, R., Panda, G., 2014: Forecasting of currency exchange rates using an adaptive arma model with differential evolution-based training Journal of King Saud University-Computer and Information Sciences, 267-18.

Sellers, P.J., Hall, F.G., Asrar, G., Strebel, D.E., Murphy, R.E., 1988: The first ISLSCP Field Experiment (FIFE), Bull. Amer. Meteorol. Soc., vol. 69, no. 1, pp. 22-27.

Sentinel Hub by Sinergise (Sinergise), 2020: https://www.sentinel-hub.com/eoproducts/evi-enhancedvegetation-index-0 (28 February 2019).

Shao, Z., Zhang, Y., Zhang, L., Song, Y., Peng, M., 2016: Combining Spectral and Texture Features Using Random Forest Algorithm: Extracting Impervious Surface Area in Wuhan, The International Archives of the Photogrammetry, Remote Sensing and Spatial Information Sciences, Volume XLI-B7, 2016 XXIII ISPRS Congress, 12-19, Prague, Czech Republic.

Streiling, S., Matzarakis, A., 2003: Influence of Singleand Small Clusters of Trees on the Bioclimate of a City: A Case Study, Journal of Arboriculture, Say1:29 (6), 309-316.

Tonyaloğlu, E. E., 2019: Kentleşmenin Kentsel Termal Çevre Üzerindeki Etkisinin Değerlendirilmesi, Efeler ve İncirliova (Aydın) Örneği, Türkiye Peyzaj Araştırmaları Dergisi,2019, 2:1, $1-13$.

Turkish State Meteorological Service (TSMS), 2018: Data Normals of Provinces (1929-1028). Retrieved from https://www.mgm.gov.tr/veridegerlendirme/il-ve-ilceler istatistik.aspx?m=ISTANBUL, (12 January 2019).

Turkish Statistical Institute (TURKSTAT), 2018: Population by years, age group and sex, 1935-2018. http://web.turkstat.gov.tr/UstMenu.do?metod=temelist (1 January 2019)

Wan, Z.S.H., Hulley, G., 2015: MOD11A2 MODIS/Terra Land Surface Temperature/Emissivity 8-Day L3 Global $1 \mathrm{~km}$ SIN Grid V006. NASA EOSDIS Land Processes DAAC.

Wang L, Zou H, Su J, Li L., 2013: Chaudhry, S., An arima-ann hybrid model for time series forecasting Systems Research and Behavioral Science, 30, pp. 244-259.

Weng, Q., Firozjaei, M.K., Sedighi, A., Kiavarz, M., Alavipanah, S.K., 2018: Statistical analysis of surface urban heat island 
intensity variations: A case study of Babol city, Iran. GIScience \& Remote Sensing, 56, 4, 576-604.

Weng, Q., Lu, D., Schubring, J., 2004: Estimation of land surface temperature-vegetation abundance relationship for urban heat island studies. Remote Sensing of Environment, 89, 467-483.

Yin, F., Deng, X., Jin, Q., Yuan, Y., Zhao, C., 2014: The impacts of climate change and human activities on grassland productivity in Qinghai Province, China. Frontiers of Earth Science, 8(1), 93103.

Zha, Y., Gao, J., Ni, S., 2003: Use of normalized difference builtup index in automatically mapping urban areas from TM imagery. International Journal of Remote Sensing, 24(3), 583594.

Zhu, L.Q., Zhu, W.B., 2012: Research on effects of land use/cover change on soil erosion. In Advanced Materials Research (Vol. 433, pp. 1038-1043). Trans Tech Publications Ltd. 